\title{
PÓS-MODERNIDADE E EDUCAÇÃO: UMA INCURSÃO SOB A ÉGIDE DO MERCADO?
}

\author{
Acácio Nascimento Figueredo \\ Nucleo de Pesquisa Sociedade e Educação - NPSE/UFS \\ HISTEDBR - GT - Sergipe \\ acacioian@zipmail.com.br
}

\section{RESUMO}

O texto ora proposto busca analisar os conceitos e a relação pós-modernidade e educação no âmbito da História da Educação. Evidencia que as diversas áreas da realidade humana; social, política, econômica e cultural estão intrinsecamente ligadas sob a égide do mercado. Esse processo objetivamente se insere em políticas privatista no campo educacional. Outrossim em prática fragmentadas na vida social e no desenvolvimento de práticas individualistas. A metodologia desenvolvida foi a revisão da literatura. Tem como objetivos aprofundar os conceitos e o processo histórico da pós-modernidade e sua relação com a educação, assim como incursão desse processo sob a égide do mercado. Em linhas gerais podemos concluir que a pós-modernidade no atual contexto da globalização do mercado insere-se no âmbito da educação em geral e da História da Educação em particular. A influência dos valores e princípios do campo pós-moderno, ou seja, o individualismo, a fragmentação das relações sociais, a determinação do mercado nas políticas sociais requer uma lógica alternativa de um fazer cientifico crítico.

Palavras-chave: pós-modernidade; educação; globalização

\section{POSTMODERNITY AND EDUCATION: A INCURSION UNDER MARKET AEGIS?}

\begin{abstract}
The proposed text aims to analyze the concepts and postmodernity respect and education as part of the History of Education. Shows that the various areas of human reality; social, political, economic and cultural are intrinsically linked under the umbrella of the market. This process objectively falls in privatizing policies in the educational field. Furthermore fragmented into practice in social life and development of individualistic practices. The methodology was the literature review. It aims to deepen the concepts and the historical process of post-modernity and its relationship to education as well as incursion of this process under the aegis of the market. Generally speaking we can conclude that postmodernity in the current market globalization context is part of the field of education in general and particularly in the History of Education. The influence of the values and principles of the postmodern field, ie individualism, fragmentation of social relations, the determination of the market in social policies requires a logical alternative to a critical scientific do.
\end{abstract}

Keywords: postmodernity; education; globalization

A relação educação e pós modernidade na atualidade põe uma necessidade fundamental ao aprofundamento conceitual e histórico. A essência desse texto busca tratar essa problemática de forma clara e real. Hoje muitos denominam a pós- modernidade na educação de forma espontânea e abstrata sem ir as fontes históricas reais e ao 
desenvolvimento de conceitos. Alguns dizem tal ator é pós moderno. Outros dizem tal prática pedagógica é pós-moderna. Tal texto é pós-moderno sem de fato denominar ou aprofundar tal conceito e situá-lo na história.

Hoje na educação logo no inicio podemos dizer que um texto, ou uma ideia pedagógica é pós-moderna no que ficou ao longo do tempo sendo conhecida como história cultural; história nova, história das mentalidades. Esse conjunto de denominações quero arriscar a chamar de pós-moderno.

Arrisco ainda a ideia de que um processo de hegemonia na educação no Brasil traz de tempo em tempo, a necessidade de imposição de determinadas ideias pedagógicas; o que contribui para a manutenção das desigualdades sociais, culturais, políticas e educacionais. Essa desigualdade revestida de uma dita pós-modernidade no lugar de avançar, só tem atrasado o processo educacional nesse país. As ideias que se tornam práticas efetivas nos programas educacionais têm ao longo do tempo impossibilitado o desenvolvimento de novas ideias e práticas educacionais. Depois do tão proclamado construtivismo agora está em moda o Alfa e Beto, Ensino Médio Inovador. Na Educação Infantil o desenvolvimento do Positivo. No fundo essas práticas estimulam a participação da iniciativa privada no interior da escola pública. São programas, modelos, pacotes educacionais que não estão em nada preocupados com o desenvolvimento cultural das crianças, jovens e adultos da classe que vive do trabalho.

Quero destacar que esse processo tem um viés ideológico que vem do desenvolvimento de ideias pedagógicas desde a graduação, até a pós-graduação; desde as pesquisas em instituições educacionais, ONGs, entre outras. Basta verificar muitos trabalhos no mestrado e doutorado que parece mais uma narrativa, do que um trabalho de pesquisa sólido, onde o que prevalece é o empiricismo narrativo e não as fontes históricas reais. Há uma verdadeira tentativa de uma área de autores pós-modernos em impor um pensamento único, cuja ideia central é eliminar os clássicos com a justificativa que os mesmos já estão ultrapassados para interpretar o presente, assim defendem o fim da história, o fim da centralidade do trabalho como categoria de análise, Vale ressaltar que há honrosas exceções que ainda conseguem possibilitar ideias pedagógicas com base nos clássicos e propor alternativas claras ao pensamento único, articulam coletivos para o enfrentamento de ideias e práticas educacionais conservadoras.

Depois dessa inicial abordagem, agora farei uma breve análise conceitual e histórica sobre a relação educação e pós modernidade. Desde já podemos aludir que esta relação na prática social orienta-se por um processo de fragmentação das ações, numa cultura supérflua, sem fundamentos, ligadas ao senso comum. Esse processo não possibilita um aprofundamento da prática educativa dos educadores em geral, e o que de pior há nas relações sociais e culturais acaba refletindo no interior das práticas pedagógicas na escola, ou na gestão escolar como um todo. Isso só tem reforçado práticas autoritárias e pouco contribui para o desenvolvimento e ampliação do processo de ensino e aprendizagem, sendo reforçado por salários baixos, sindicatos inoperantes, entre outros aspectos que espero aprofundar posteriormente no texto. Inicialmente farei uma análise breve sobre a pós-modernidade e logo após sua relação com a educação.

No livro As Origens da Pós-Modernidade podemos destacar o processo histórico da pós-modernidade, desde os primórdios, já no interior do modernismo até a atualidade. Perry Anderson (1999: p.9-11) infere que "“Pós-modernismo", como termo e ideia, supõe o uso corrente de "modernismo". Ao contrário da expectativa convencional, ambos nasceram numa periferia distante, e não no centro do sistema cultural da época: não vem da Europa ou dos Estados Unidos, mas da América Hispânica em 1890" 
Assim também a ideia de um "pós-modernismo" surgiu pela primeira vez no mundo hispânico, na década de 1930, uma geração antes do seu aparecimento na Inglaterra ou nos Estados Unidos. Foi um amigo de Unamuno e Ortega, Federico de Onis, quem imprimiu o termo pós-modernismo. Usou-o para descrever um refluxo conservador dentro do próprio modernismo: a busca do refugio contra o seu formidável desafio lírico num perfeccionismo do detalhe e do humor irônico, em surdina cuja principal característica foi a nova expressão autêntica que concedeu as mulheres. Onis contrastava esse modelo - de vida curta, pensava - com sua sequela, um ultramodernismo que levou os impulsos radicais do modernismo a uma nova intensidade numa série de vanguardas que criavam então uma poesia rigorosamente contemporânea de alcance universal. A famosa antologia de poetas de língua espanhola organizada por Onis segundo esse esquema foi publicada em Madri em 1934, quando a esquerda assumiu o comando da republica na contagem regressiva para a Guerra Civil. Dedicada a Antonio Machado, seu panorama do "Ultramodernismo" terminava em Liorca, Vallejo, Borges e Neruda.

Nesse mesmo livro vale ressaltar duas características essenciais na ideia pósmoderna. A pluralidade com viés ecléticos e o mercado como determinantes na vida social. É importante ressaltar que essas características estão presentes de forma efetiva na realidade objetiva material da atualidade. A pluralidade intrínseca ao ecletismo e ao relativismo. E o mercado como espaço de dominação mundial com a participação efetiva de grandes corporações mundiais. Segundo Perry Anderson (1999:p.31) "Charles Jencks reverteu sem receio a oposição entre os termos de Onis. Era o pós - modernismo... Em meados da década de 1980 Jencks festejava o pós-moderno como uma civilização mundial de tolerância pluralística e opções superabundantes, uma civilização que "tornava sem sentido" polaridades ultrapassadas como "esquerda e direita, capitalista e classe operária". Numa sociedade que a informação vale mais que a produção. Não há mais vanguarda artística, uma vez que não há inimigo a derrotar na rede eletrônica global. Nas condições emancipadas da arte atual, há em vez disso inúmeros indivíduos em Tóquio, Nova York, Berlim, Londres, Milão e outras cidades mundiais que se comunicam e competem, assim como estão no mundo financeiro.

Perry Anderson (1999: p. 39-54) sobre a essência do campo cientifico da História e da própria reflexão filosófica vai mostrar que "Com a Condição Pós Moderna" Lyotard anunciou o eclipse de todas as narrativas grandiosas. Aquela cuja morte ele procurava garantir acima de tudo era, claro, a do socialismo clássico...

Com a mudança de conjuntura nos anos 80 - a euforia do boom do governo Reagan e a triunfante ofensiva ideológica da direita que culminou com o colapso do bloco soviético no final da década -, essa posição perdeu toda a sua credibilidade. Longe de terem desaparecidos as grandes narrativas parecia que pela primeira vez na história o mundo caia sob o domínio da mais grandiosa de todas - uma história única e absoluta de liberdade e prosperidade, a vitória global do mercado...

As intervenções coincidentes de Lyotard e Habermas pela primeira vez deu a campo o selo da autoridade filosófica. Mas suas próprias contribuições foram estranhamente indecisas. A formação original dos dois pensadores foi marxista, mas é espantoso o pouco que daí trouxeram para as suas análises da pós-modernidade. Também não tentaram uma verdadeira interpretação histórica do pós-moderno que fosse capaz de defini-lo no tempo ou no espaço... O campo no entanto, mostrava outra espécie de unidade era ideologicamente consistente. A ideia do pós-moderno na maneira como foi assumida nessa conjuntura, era, de uma forma ou de outra apanágio da direita... não podia mais haver nada mais que o capitalismo. O Pós-moderno foi uma sentença contra as ilusões alternativas. 
Nessa perspectiva Perry Anderson contribui efetivamente para o processo histórico da vida social, uma vez que esses aspectos apresentados por ele estão presente ainda hoje influenciando todos os campos o político, o econômico, o cultural, o social, o educacional etc.

José Luis Sanfelice (2009: PP. 3-12) ao inferi nesse livro de "Perry Anderson (1999) lembra-nos que o termo pós-modernidade, já usado anteriormente no mundo das artes teve sua primeira abordagem filosófica quando o filósofo J.F.Lyotard publicou, em 1979, sua obra A condição pós-moderna"

Esta era a situação quando Fredric Jameson deu sua primeira conferência sobre pósmodernidade em 1982 e que o tornaria referência na área. Cinco lances do seu discurso foram decisivos... O lance final: qual é a atitude mais adequada ante a pós-modernidade? Lamentar-se porque seria uma corrupção do moderno? Celebrá-la como uma emancipação? Ou evitar uma postura moralista? ... A tarefa dialética seria abrir caminho por meio dela, de forma tão completa que nosso entendimento da época emergisse transformado. Uma compreensão totalizante do novo capitalismo ilimitado - teoria adequada a escala global de suas conexões e disjunções - continua sendo o irrenunciável projeto marxista.

As considerações acima, abstraídas da obra citada de Perry Anderson (1999), são suficientes no momento. Enfim, o que mais nos interessa é o quadro que ele delineia para a denominada pós-modernidade, ou seja, a sua base material objetiva na ordem econômica do próprio capital... Pós modernidade, para nós, portanto é um fenômeno, dentre outras coisas, que expressa uma cultura da globalização e da sua ideologia neoliberal.

Se pós modernidade e globalização se imbricam, como foi lembrado por Anderson, ao lembrar Jameson, de que modo podemos relacionar as faces deste fenômeno com a educação?

A globalização tem pelo mundo afora, dentre outros suportes materiais, também o suporte de uma ideologia que se convencionou denominar de neoliberal... As teses centrais do neoliberalismo, considerando um conceito de mercado como eixo das relações sociais, bem como a defesa do estado mínimo contra o estado bemfeitor, tem sido orientadora das políticas sociais e muito especialmente das políticas educacionais. Pós-modernidade, globalização e educação relacionam-se pela lógica do mercado.

Essas considerações de Sanfelice trazem o alerta para nós educadores estarmos ligados as mudanças ocorridas nos últimos anos no interior da escola pública, de forma especifica; e no sistema educacional de forma geral aqui no Brasil. Há uma tentativa de forma sutil de privatizar as instituições educacionais públicas. Seja no âmbito da gestão escolar, seja no âmbito dos programas educacionais. Em Sergipe por exemplo na Secretaria Estadual de Educação tentaram implantar o Maresguia - um compromisso de gestão que iria destruir qualquer tentativa de implantação da gestão democrática. No âmbito dos programas surge o alfa\&beto, destruindo praticamente a possibilidade a autonomia da prática pedagógica das professores e professores. Há uma tentativa de implantar de goela a baixo um modelo privatista da educação, portanto imbricado diretamente com o mercado.

Sobre o que arrisquei inferi acima, acredito ser essencial ir no âmago da teoria do pós-modernismo para referendar, isto é, fundamentar o dito até aqui. Quero ressaltar, o que for apresentado relativo a educação, também pode ser ampliado para outras áreas de conhecimento, para outras práticas sociais, principalmente no campo da cultura, do trabalho e das relações humanas em geral. De início exponho as ideias de Fredric Jameson no seu trabalho intitulado "Pós Modernismo: a lógica cultural do capitalismo tardio (1997, p.16-18 )". Ele traz análises fundantes e essenciais sobre pós-modernismo. Segundo Jameson "A teoria do pós-modernismo parece ser necessariamente imperfeita ou impura; no caso, devido a contradição implícita no fato de que Oliva (ou Lyotard) tenha que apresentar sua 
percepção de todos os aspectos significativos do desaparecimento das narrativas mestras em forma de narrativa".

Se é possível, como na prova de Gódel, demonstrar a impossibilidade lógica de uma teoria internamente coerente do pós-modernismo - um antifundacionismo realmente livre de todo fundamento, um não-essencialismo sem um menor vestígio de uma essência - , isso é uma questão especulativa. A resposta empírica é que nenhuma teoria com essas características apareceu até agora - todas replicam, já no próprio título, uma mimésis do modo como são parasitárias de outro sistema ( no mais das vezes do próprio modernismo), cujos traços residuais, assim como valores e atitudes inconscientemente reproduzidos, tornam-se, então, indicações preciosas da impossibilidade de emergência de uma cultura totalmente nova. Apesar do delírio de alguns dos seus celebrantes e apologistas (cuja euforia, no entanto, é, em si mesma, um interessante sintoma histórico), uma cultura verdadeiramente nova somente poderia surgir através da luta coletiva para se criar um novo sistema social. A impureza constitutiva de toda teoria do pós-modernismo (assim como o capital, ela tem que manter uma distância interna de si mesma, tem que incluir o corpo estranho de um conteúdo alheio) confirma, então, um dos achados da periodização que precisa sempre ser reiterado: o pós-modernismo não é a dominante cultural de uma ordem social totalmente nova (sob o nome de sociedade pós-industrial, esse boato alimentou a mídia por algum tempo), mas é apenas reflexo e aspecto concomitante de mais uma modificação sistêmica do próprio capitalismo. Não é de espantar, então, que vestígios de velhos avatares - tanto do modernismo como até do próprio realismo - continuam vivos, prontos para serem reembalados com os enfeites luxuosos de seu suposto sucessor.

Mas esse retorno imprevisível da narrativa como a narrativa sobre o fim das narrativas, esse retorno a história em meio aos prognósticos do desaparecimento do télo histórico, sugere uma segunda característica relevante da teoria do pós-modernismo: o modo pelo qual qualquer observação virtual sobre o presente pode ser mobilizada para se investigar o próprio presente, e pode ser utilizada como sintoma e índice da lógica mais profunda do pós-moderno, que assim se torna, imperceptivelmente, sua própria teoria e a teoria de si mesmo [...] Porém, o delírio de apelar para qualquer elemento virtual do presente com o intuito de provar que esse é o tempo singular, radicalmente distinto de todos os momentos anteriores do tempo humano, parece-nos, por vezes, abrigar uma patologia distintamente auto referencial, como se nosso completo esquecimento do passado se exaurisse na contemplação vazia, mais hipnótica, de um presente esquizofrênico, incomparável por definição.

Considero o texto de Jameson muito elucidativo. Particularmente acredito que traz o cuidado em apreender o processo histórico na atualidade. Ele faz atentar para a necessidade de conhecer o processo, os fatos sociais, políticos, econômicos, estéticos e diria educativo de cada época. Atenta principalmente para não ficarmos presos ao presente, sem ligar aos acontecimentos passados. No campo da história da educação por exemplo o que isso pode indicar? Indica, de acordo com o pós-modernismo que apenas hoje é o que importa. $\mathrm{O}$ processo anterior não tem importância, ou seja, por exemplo, a influência dos Jesuítas e todas as ideias pedagógicas ao longo da história do Brasil não é relevante para entender o presente. O importante é absorver as ideias dos ideários pós-modernos e neoliberais de hoje. Práticas pedagógicas anteriores, como por exemplo a proposta educativa do sistema Paulo Freire só foram válidas para o início da década de 1960. Nessa acepção até o processo histórico que destruiu essas práticas não são considerados. Não precisa entender o porquê do golpe civil militar que não apenas destruiu o sistema Paulo Freire, a Campanha Nacional de Alfabetização, mas diversas práticas pedagógicas no campo de pesquisa e 
desenvolvimento da política educacional daquele período até a atualidade. Indica principalmente também a crítica a este estado de coisas.

Os grupos hegemônicos, principalmente da década de 1990 para cá com a ampliação das ideias da Escola dos Analles, e da história nova, a nível geral percebe-se claramente a busca da construção do pensamento único. Quem é marxista, ou defensor de ideias iluminista moderna no âmbito da ciência, da economia e da política tende a ser considerado ultrapassado, suas ideias já não atendem a realidade do presente. E o próprio presente fica sem vínculo com o passado. Desloca-se os conceitos e leis universais para conceitos que fortalecem a fragmentação dos espaços e dos sujeitos. Ou até a falta de conceitos. Para ilustrar o que estou dizendo apresento os argumentos de Stuart Hall no livro "A identidade cultural na pós-modernidade". Aqui o autor reforça sua retórica ao escrever sobre a identidade. Esse processo de mudança ao longo do texto elaborado por Stuart Hall arrisco a dizer que reforça as práticas e interesses da intrínseca relação entre ciência, educação e mercado.

Segundo HALL (2011: p. 24) "Tentar mapear a história da noção de sujeito moderno é um exercício extremamente difícil. A ideia de que as identidades eram plenamente unificadas e coerentes e que agora se tornaram totalmente deslocadas é uma forma altamente simplista de contar a história do sujeito moderno".

Eu a adoto aqui como um dispositivo que tem o propósito exclusivo de uma exposição conveniente. Mesmo aqueles que subscrevem inteiramente a noção de um descentramento da identidade não a sustentariam nessa forma simplificada. Deve-se ter essa qualificação em mente ao ler este capítulo. Entretanto, essa formulação simples tem a vantagem de me possibilitar (no breve espaço deste livro) esboçar um quadro aproximado de como, de acordo com os proponentes da visão do descentramento, a conceptualização do sujeito moderno mudou em três pontos estratégicos, durante a modernidade. Essas mudanças sublinham a afirmação básica de que as conceptualizações do sujeito mudam e, portanto, têm uma história. Uma vez que o sujeito moderno emergiu num momento particular (seu "nascimento") e tem uma história, segue-se que ele também pode mudar e, de fato, sob certas circunstâncias, podemos mesmo contemplar sua "morte".

É agora um lugar comum dizer que a época moderna fez surgir uma nova forma e decisiva de individualismo, no centro da qual erigiu-se uma nova concepção de sujeito individual e sua identidade.

Para Stuart Hall (2011: p.30) "grande parte da história da filosofia ocidental consiste de reflexões dessa concepção do sujeito, seus poderes e suas capacidades. René Descartes para expor a concepção do sujeito racional. John Locke que, cria o indivíduo soberano. "Ele era o sujeito da modernidade".

As leis clássicas da economia política, da propriedade, do contrato e da troca tinham de atuar, depois da industrialização, entre as grandes formações de classe do capitalismo moderno"

O empreendedor individual da Riqueza das ações de Adam Smith ou mesmo d'O capital de Marx foi transformado nos conglomerados empresariais da economia moderna. $\mathrm{O}$ cidadão individual tornou-se enredado nas maquinarias burocráticas e administrativas do estado moderno.

Á frente o autor expõe cinco ideias sobre o sujeito, segundo a qual "aquelas pessoas que sustentam que as identidades modernas estão sendo fragmentadas argumentam que o aconteceu à concepção do sujeito moderno, na modernidade tardia, não foi simplesmente sua desagregação, mas seu deslocamento".

Elas descrevem esse deslocamento através de uma série de rupturas nos discursos do conhecimento moderno. Nesta seção farei um rápido esboço de cinco grandes avanços na 
teoria social e nas ciências humanas ocorridos no pensamento no período da modernidade tardia (a segunda metade do século XX), ou que sobre ele tiveram seu primeiro impacto, e cujo maior efeito, argumenta-se foi o descentramento final do sujeito cartesiano.

A primeira descentração importante refere-se as tradições do pensamento marxista. Os escritos de Marx pertencem, naturalmente, ao século XIX e não ao século XX... O segundo dos grandes descentramentos no pensamento ocidental do século XX vem da descoberta do inconsciente por Freud... O terceiro está associado com o trabalho do linguística estrutural... O quarto descentramento principal da identidade e dos sujeito ocorre no trabalho do filósofo e historiador francês Michel Foucalt... O quinto descentramento que os proponentes dessa posição citam é o impacto do feminismo, tanto como uma crítica teórica quanto um movimento social. (Idem, p. 44).

Com a ideia de descentramento o autor desloca as grandes ideias da modernidade com o pressuposto que elas só tiveram validade até o século XIX. Assim o conjunto de correntes filosóficas para esse autor pós-moderno, deixam de ter predominância. Quero destacar aqui que ao discordar do pensamento pós-moderno, da construção teórica e prática, não estou no outro polo reforçando um pensamento único. Quero apenas expor a concordância da teoria marxiana como possibilidade de análise da realidade na atualidade. Como também a possibilidade do pensamento moderno em geral. Os pós-modernos também certamente tem seu espaço para aqueles que fazem a análise fragmentada da realidade. Prefiro analisar a realidade na sua totalidade não apenas para interpretá-la, mas transformá-la.

No sentido de aprofundar campos intrínsecos a pós-modernidade, devido a limitação desse texto, apenas faço uma breve menção ao campo da História Cultural Para Sérgio Castanho (2006, p. 139) "Tradicionalmente, a história ocupa-se, de um lado, com as bases materiais e sociais da existência humana (a economia, a política e a sociedade), e de outro, com as ideias mediante as quais os homens representam essa existência (as ideias, o pensamento, a filosofia, a literatura e as artes). Fruto de uma construção tipicamente moderna que se inicia como "atitude" no século XVIII, com as Luzes, e se consolida como "disciplina cientifica no século XIX".

Sérgio Castanho (2006, p.143-151) nesse livro ainda vai inferir que "É no século $\mathrm{XX}$ que a história cultural, quer como história das ideias, quer como história intelectual, ou ainda como história cultural propriamente dita irá eclodir. Um retorno a filosofia da história de viés idealista irá marcar o historicismo de Dilthey, formulado na última década do século XIX de fundas repercussões no campo da história cultural"

O início do século XX, pouco antes e pouco depois da $1^{\text {a }}$ guerra mundial de 1914 1918, é marcado por um coquetel intelectual de idealismo, historicismo, positivismo e psicanálise, enquanto na área do marxismo, suas primeiras gerações após a morte de Engels em 1895... tratava-se de repensar os instrumentos de análise do modo de produção, de sorte a poder compreender como ele saía das conjunturas de baixa para novos saltos à frente. Além disso era o momento de se iniciar uma teoria política marxista. Com essa agenda, o campo do marxismo acabou deixando para os anos após 1930, após a crise do capitalismo mundial subsequente ao crack da Bolsa de Nova York em 1929 o tratamento em profundidade da questão ideológica. É a partir daí, da obra de Antonio Gramsci, Georg Lukács e dos teóricos da chamada Escola de Frankfurt, notadamente Karl Korsch, que a área cultural passará a interessar seriamente ao pensamento marxista.

Já no período posterior, que cobre todo o restante do século XX, de 1930 até nossos dias, podemos vislumbrar duas fases, a primeira indo até os anos de 1970, com uma presença destacada senão hegemônica do marxismo, a segunda abrangendo os anos de 1970, 1980 e 1990, marcada pela crise de hegemonia acadêmica do marxismo e a ascensão, 
não só artístico canônica, mas filosófica e mesmo historiográfico-cultural, do pósmodernismo. Um momento particularmente importante na evolução do marxismo no século $\mathrm{XX}$, com repercussões significativas na historiografia cultural, foi o representado pela Escola Inglesa, se assim se pode referir ao grupo quase sempre desconexo de pensadores e historiadores que gravitaram em torno do Partido Comunista Britânico, durante os anos de 1950 e 1960: Eric Hobsbawn, Raymond Williams e, sobretudo, Eduard P. Thompson...

A história cultural, no ultimo quartel do século XX - dos anos de 1970 aos de 1990 - dentro de uma incrível pluralidade de denominações, de ênfases particularíssimas neste ou naquele aspecto, desenvolveu-se segundo uma linha de tensão, muito bem apreendida por Francisco Falcon (1997, p.114), que separa, de um lado, as abordagens ou tendências historiográficas que de algum modo relacionam o universo das ideias - ou intelectual com o da sociedade; e, de outro lado, os que rejeitam ou ignoram tais relações, trabalhando as ideias apenas em seu suporte textual, "como discurso ou mensagem, a partir de pressupostos linguísticos, hermenêuticos ou literários". Denomino as primeiras contextualistas, porque de uma maneira ou de outra, referem as ideias ao contexto social em que são geradas, e as segundas, textualistas, porque preocupadas sobretudo com a "economia interna" do mundo ideal tal como se manifesta no texto que é seu suporte.

Outras empreitadas dentro do âmbito do marxismo , são: o estruturalismo marxista de Louis Althusser; e nos nossos dias, o marxismo pós-moderno de Fredric Jameson particularmente preocupado com a questão ideológica.

Numa área ambígua entre o textualismo e o contextualismo, mas com evidente primazia ao texto, razão por que é de dificil senão impossível o diálogo com o marxismo, temos o trabalho de Roger Chartier, especialmente sua A História Cultural(1990) no qual emprega as noções de práticas e representações; e o de Pierre Bourdieu, mais voltado ao contexto, o que facilita sua interlocução com o materialismo histórico.

Num outro campo é o do "textualismo", cujos fundamentos teóricos podem ser encontrados na "introdução" à Arqueologia do saber (1997), de Michel Foucault. Numa confrontação com Braudel, Foucault denuncia a história da longa duração... Foucault mostra que a história mudou sua posição acerca do documento: ela considera como sua tarefa primordial, não interpretá-lo, não determinar se diz a verdade nem qual é seu valor expressivo, mas sim trabalhá-lo no interior e elaborá-lo.

Com esta inversão de rumos, o documento transforma-se em "texto" e o texto passa a ser a finalidade do historiador. Não lhe importa saber se o texto reflete fielmente uma realidade que lhe é exterior, isto é, não importa "determinar se diz a verdade". O próprio texto é a realidade e, como tal, deve ser trabalhado.

Considero que a história cultural com o viés predominante textualista vem ao longo do tempo influenciando a história da educação principalmente no âmbito da pós graduação nos trabalhos de mestrado e doutorado em que há diversos estudos que buscam nos documentos, não a história real do processo em que a educação está inserida, mas objetos específicos como pessoas, escolas, diários escolares, currículo, ou seja há uma predominância na micro história de forma narrativa, sem considerar o processo histórico, social e as contradições inerente ao documento. E o pior muitos trabalhos não consideram os clássicos seja no campo pedagógico, filosófico, sociológico, e outras áreas do conhecimento que fundamentam o processo real e histórico em que a educação se insere.

Sobre a relação entre a História Cultural e a Educação, Sérgio Castanho (Id, ibidem, p.152) mostra que "em muitas classificações, no passado, a educação era compreendida dentro do campo da história cultural. É que a história da educação, ainda que praticada desde o século XIX, demorou a se firmar como disciplina relativamente autônoma" 
Para o autor dentro desta perspectiva "a história cultural tem seu âmbito próprio, sem deixar de ser história. E a história da educação, depois de um longo itinerário, acaba também por se constituir como campo autônomo, dotado de objeto próprio".

É sabido - e isso se repete a todo momento na literatura histórico-educacional de nossos dias - que a história da educação anterior aos anos de 1970 e 1980 preocupava-se sobretudo com o dever ser da educação, representado pelas ideias pedagógicas, pelas propostas que pedagogos e pensadores apresentavam a educação... Nos anos de 1970-1980, a história da educação conheceu uma reação parcial a estes estados de coisas, passando a relacionar escola e sociedade...

Mas foi nos anos de 1990 que a reação se fez sentir de forma mais ampliada. Essa reação corre por duas vias: uma tendia a prestar mais atenção a realidade externa que condicionava a realidade escolar; a outra tendia a analisar de dentro aqueles aspectos ainda sociais - gerado ainda por esta realidade escolar, entendida agora como cultura com seus trações e exigências, com sua própria lógica interna... No entanto, a força teórica e metodológica do materialismo histórico, isto é, sua validade como instrumento de acesso e de explicação do fenômeno educativo em mudança, depende em grande medida da sua capacidade de adaptação aos novos objetos, aos novos problemas, e até mesmo aos métodos que chegam junto com as novas temáticas. Já vimos como o marxismo de um Thompson, por exemplo, ao defrontar-se com uma nova questão para o qual os velhos instrumentos não davam conta, acabou por rever-se, por reformular-se, encontrando novos caminhos. O mesmo seguramente deverá ocorrer coma a história da educação, se o enfoque quiser dar conta de outras questões além das extremamente válidas e importantes, do pensamento pedagógico e da política educacional.

Até aqui o texto tem como propósito arriscar uma tentativa de desenvolver uma ideia da relação história cultural e história da educação no âmbito da pós-modernidade e sua crítica. Não é uma tarefa fácil, e certamente há trabalhos que já o fizeram com maior profundidade, entretanto na prática educativa que me insiro, seja no âmbito escolar, seja em outras instituições educativas como ONGs e Movimentos Sociais que efetivamente participei e nos dias de hoje, participo, assim como instituições de pesquisa que sou membro percebo claramente a importância de elucidar questões importantes na prática social, cultural e educativa dessas instituições. Acredito que é no coletivo de educadores e pesquisadores que podemos fortalecer o desenvolvimento do saber cientifico, em detrimento do saber do senso comum vulgar. Se não somos radicais, não vamos a fundo das questões, torna-se muito difícil uma transformação qualitativa do processo educativo historicamente produzido. Enquanto a onda pós-moderna que reforce os pequenos objetos de estudos e pesquisas sobre a educação, além da fragmentação das práticas educativas, sociais e culturais dos sujeitos que participam; ficaremos assistindo a banda passar? Como diria Chico Buarque. Acredito que não. É no movimento dialético da totalidade e contraditório que avançamos em alternativas concretas.

Sobre este conjunto de coisas José Claudiney Lombardi (2006:189), após a exposição das ideias de Sandra Jatahi Pesavento e Ronaldo Vainfas vai inferi que "a abundância de citações é proposital, para deixar a autora falar, numa tentativa para deixar explícito que não estou forjando os termos de modo que caracterize essa nova história cultural"

como vinculada, mais que isso, imersa na pós-modernidade. O que isso decorre em termos metodológicos e teóricos ficou explicitado anteriormente e uma síntese desses pontos podem ajudar a esclarecer de onde falam os historiógrafos "novidadeiros" da cultura. Trata-se de uma abordagem que difusamente defende um conjunto de postulados que alinha a nova história cultural a uma abordagem anticientificista e obscurantista "tão 
presente em muitos dos cultores da autodenominada Nova História (Cardoso, 1997, p.3), seguramente vinculada a pós-modernidade. Em linhas gerais, os principais traços que marcam essa vinculação são os seguintes: antirrealismo, ceticismo, subjetivismo, centralidade no discurso, abandono da busca pela verdade, a história como discurso, contrapondo-se a história como ciência, enfim, a história como um metanarrativa - a história como literatura.

Logo em seguida Lombardi (Ibidem, p.200) após analisar os textos marxianos sobre o trabalho e a consciência humana vai inferi que "em vista dessas observações de modo esquemático, posto que se trata de conteúdo já explicitado, não estou contra o uso do conceito de cultura, mas me posiciono contrário:" a tratar a realidade de modo fragmentário; a tratar a ciência como uma justaposição de disciplinas, cada qual em sua especialização; a tomar cada ciência como tendo objeto e método próprio de investigação.

Ao contrário dos posicionamentos novidadeiros, estou a defender: uma postura epistêmica que tome a realidade em sua totalidade como objeto de investigação; que sempre e necessariamente tome a rica articulação entre o universal e o singular, entre o particular e geral, mesmo quando se tratar de desvelar um objeto particular de investigação; que teoricamente busque a articulação entre a infra e superestrutura, com todas as necessárias determinações e mediações.

Diante de tais considerações penso que a história cultural vem ao longo do tempo, principalmente após os anos de 1990 assumindo uma posição, seja no curso de licenciaturas, principalmente em história e pedagogia, seja nos programas de mestrado e doutorado, muito mais voltada, ao que o autor acima referido chama de novidadeiros, assumindo a nova história com seus novos objetos de estudos e pesquisas como central no âmbito da educação brasileira. Nesse sentido a história da educação seguindo este período de tempo pouco contribui para a transformação efetiva da situação educacional no Brasil. Ao contrário às mudanças ocorrem no âmbito da influência do mercado às políticas educacionais, portanto, tornando privado o que é público. Isso é muito sutil. Na verdade os agentes da história da educação novidadeira estão diretamente ligados aos agentes do mercado no âmbito da educação. Suas pesquisas de fato contribuem muito mais para uma história monumento. Para grandes figuras da elite brasileira, ou simplesmente suas análises abordam fragmentos de uma realidade como um grupo escolar, seu histórico particular, sem fazer a relação com o processo social, histórico, político e econômico em geral.

Raras exceções buscam a análise na ciência da história, voltada a interpretação da realidade na sua totalidade. Ressalto mais uma vez que os poucos que fazem essa mediação mais ampla têm conseguido articular em grupos de pesquisa ideias e ações voltadas a dialogar com os sujeitos concretos que fazem a educação possibilidades de alternativas objetivas tanto a transformação da educação, como a transformação cultural e social em geral.

Sobre o debate em torno da História e posteriormente da História da Educação destaco os anais do II Seminário do Grupo de Estudos e Pesquisas História, Sociedade e Educação em Sergipe, com o título "A Pesquisa Histórico-Educacional: Impasses e Desafios". José Paulo Neto no seu texto intitulado "Os desafios epistemológicos e metodológicos da pesquisa histórica". Nele NETO (2002, p.24-25) infere que "independente da concepção de História, o problema da pesquisa põe três questões relevantes"

Primeira é a questão teórica. É preciso ter clara as referências teóricas. Segundo é a consideração de que os processos históricos não se explicam e se compreendem tomados "de per si", eles têm caráter de totalidade. Eu diria que essa é a categoria heurística mais fundamental para a pesquisa contemporânea, exatamente em contraposição ao discurso pós- 
moderno. Este considera que a categoria de totalidade, além de ser inepta para apreender uma realidade pulverizada e atomizada, conduziu a formulações intelectuais totalitárias. Isso me parece um gravíssimo equivoco, a luta contra o pensamento único e o totalitarismo passam e demandam a compreensão do caráter de totalidade de todos os fenômenos sociais. Isso não significa a subestimação dos micros estudos ou dos estudos microscópicos, das pesquisas localizadas, em absoluto, não há antimomínia entre pesquisa macro e micro. . Não há pesquisa micro bem sucedida sem uma remição a totalidade social mediada por uma teoria da história. E em compensação não há pesquisa macro que seja simplesmente a cristalização e o agregado de estudos micros. Finalmente uma palavra acerca do pluralismo, do ecletismo, a importância da clareza metodológica. É-me muito cara a ideia de uma ortodoxia metodológica. E falo isso provocadoramente porque está na moda identificar ortodoxia com dogmatismo, uma coisa que nada tem a ver com a outra. A relação de ortodoxia com dogmatismo é a mesma relação que existe entre totalitarismo e a categoria heurística da realidade, ou seja, nenhuma. A ortodoxia metodológica é a clareza acerca da direção da pesquisa, sobretudo da relação constituinte no processo da pesquisa, da relação da unidade entre pesquisador e seu objeto.

Aqui arrisco meus argumentos relativos a concepção de história pós-moderna, ou seja, tal concepção vem criando a ideia das perdas do que foi construído historicamente pela humanidade: história, trabalho, ideologia, cultura universal, entre outros elementos essenciais na formação da pessoa humana e da sociedade em geral. Pretendo aqui não ser dogmático, como nos alerta o autor acima referido. Esse quadro pós-moderno vem ao longo do tempo corroendo por dentro das diversas organizações sociais, mesmo aquelas mais radicais a vinte anos atrás como movimentos sociais, ONGs; inclusive diversos intelectuais entram nestas fileiras. O que está havendo? Um fato percebo claramente. Os espaços democráticos que existiam a vinte anos atrás; do final da década de 1990 para cá, muitos já não mais existem. Aqui em Sergipe por exemplo movimentos sociais como o Movimento de Defesa da Prainha, a Associação dos Moradores do Bairro América - AMABA, ONGs como o Centro Sergipano de Educação Popular (CESEP), a SACI já não mais existem. Cabe ressaltar que essas organizações sociais desenvolveram ações efetivamente democráticas e transformadoras na luta contra o analfabetismo, o desenvolvimento de trabalhos com Educação Infantil, aonde os governos estadual e municipal não atuavam nas comunidades. Além do desenvolvimento cultural e esportivo. Outro aspecto importante foi o trabalho do CESEP na formação de lideranças dos movimentos populares em Sergipe em que gerou campanhas contra o extermínio da criança, entre outras. $\mathrm{O}$ fortalecimento dos movimentos populares através de curso de produção de material no sentido de sistematizar o conhecimento popular produzido por estes movimentos, etc. Um pouco deste processo está exposto no meu trabalho de dissertação de mestrado intitulado "A prática educativa e os princípios políticos do CESEP: processos formativos de uma ONG em Sergipe (19881998)" e em outros trabalhos de monografia de graduação e especialização. Entretanto tanto o CESEP como todas as outras organizações sociais citadas acima, em Sergipe, todas encerraram suas atividades do final dos anos de 1990 a 2008. Quis apenas explicitar um problema concreto, porém em diversas outras instituições ocorreram mudanças efetivas na atitude como sindicatos, centrais entre outras.

As crianças, jovens e adultos hoje, aonde aconteciam as atividades desenvolvidas pelas organizações sociais passam a não ter acesso a escola, as atividades culturais. $\mathrm{O}$ que cresce nos espaços acima referidos é a violência, a falta de saneamento básico e a dependência de programas do governo federal como bolsa família e outros que por mais importante que sejam não vinculam a ações mais amplas na sociedade quanto ao acesso a trabalho, cultura e escola de qualidade. Não estou querendo aqui fortalecer a ideia da 
substituição do Estado, das políticas públicas estatais, tão proclamado como Estado mínimo para as ações sociais e máximo para as ações privadas. Estou defendendo a ideia que com a destruição das organizações sociais, as práticas democráticas aí existentes foram também destruídas.

Na guisa da conclusão quero reforçar que os ideólogos da pós-modernidade na prática estão enraizados com os ideólogos neoliberais, o que afirma Newton Duarte (2006: p.75-77) após analisar o pensamento neoliberal de Frederick Hayek afirma "há uma indissolúvel relação entre as mais diversas (e elas parecem ser infinitas) formas de manifestação do pensamento pós-moderno e a realidade social do capitalismo contemporâneo, do qual o pensamento neoliberal apresenta-se como explicito defensor".

Os pensadores neoliberais não estão sozinhos nessa tarefa de reprodução, no plano ideológico, da ordem capitalista contemporânea. A eles juntam-se, mesmo sem saber, os pensadores pós-modernos. Quando afirmamos que os pós-modernos são aliados aos neoliberais mesmo sem disso terem conhecimento, estamos enfatizando que esta aliança existe mesmo que os pensadores pós-modernos acreditem estar fazendo análises críticas da sociedade contemporânea e estamos também enfatizando que alguns autores, mesmo não se apresentando como pós-modernos, e mesmo acreditando adotarem posições políticas de esquerda, podem estar endossando os postulados centrais do pós-modernismo e, desta forma, ainda que contrariamente as suas intenções, contribuindo para a reprodução da ordem capitalista neoliberal...

Nesse processo podemos ampliar para diversas possibilidades que estão intrinsecamente absorvendo o cotidiano da juventude na escola e na sociedade em geral. Cada vez fica mais difícil encontrar sujeitos efetivamente históricos, comprometidos com as questões sociais, políticas, culturais, econômicas e ideológicas de sua época. Há uma verdade quase inquestionável: as incertezas, as inverdades, a falta de projetar o futuro, a falta de conhecimento do real concreto do processo histórico. Surge a cada dia novas tecnologias; a internet e com ela, o facebook, o wathzap, o blog, o twiter... São várias realidades virtuais. $\mathrm{O}$ mundo real praticamente é substituído pelo abstrato virtual. Valores universais que até a cinco anos atrás eram importantes como a amizade, a solidariedade, entre outros são substituídos pela imensidão de amigos virtuais e um crescente individualismo.

Qual o resultado desse processo? Arrisco a dizer que contribui para o aumento da violência, da falta de noção do que seja a família, a comunidade. No campo cultural, de fato há muito tempo já se perdeu a noção do que seja de fato cultura. Há uma predominância a subjetividade atingindo os desejos e vontades. Quase some a música popular brasileira, o rock e samba de protesto, a música sertaneja de raiz, o folclore tradicional, entre outros expoentes da cultura universal, para colocar em ênfase o arrocha, a música sertaneja dita universitária, que no sentido de universidade não tem nada. Nos cursos de graduação ler apenas trechos de uma obra. Não se conhece a obra de um autor e piorou os conceitos e categorias que constrói o pensamento desse autor. Lê-se o comentário do comentário, anedotas, narrativas do cotidiano, etc.

Enfim acredito ser essencial as indagações de Sergio Paulo Rouanet (1987: p. 1112). Esse autor trás as seguintes indagações "Estamos assistindo hoje, em todo o mundo, as tendências que fazem prever o advento de um novo irracionalismo. Mas ele é mais perturbador que o antigo, porque não está mais associado a posições políticas da direita. A razão não é mais repudiada por negar realidades transcendentes - a pátria, a religião, a família o Estado - , e sim por estar comprometida com o poder"

O novo irracionalismo se considera crítico e denuncia um statu quo visto como hostil a vida. A partir de uma certa leitura de Foucault, Deleuze e Lyotard, e sob a 
influência de um neonietzscheanismo que vê relações de poder em toda parte, ele considera a razão o principal agente de repressão, e não o órgão da liberdade, como afirmava a velha esquerda.

Ora, sustento que o irracionalismo mudou de rosto, mas não mudou de natureza. Hoje como ontem, só a razão é crítica, porque seu meio vital é a negação de toda facticidade, e o irracionalismo é sempre conformista, pois seu modo de funcionar exclui o trabalho do conceito, sem o qual não há como dissolver o existente.

Essas indagações nos mostram que o desenvolvimento de um fazer cientifico critico requer um esforço de ir além do irracionalismo. Acrescento que devemos ir além do irracionalismo de todas as áreas sob a égide do mercado. Requer uma atitude radical vista a transformação de valores morais; dos aspectos culturais que supere o senso comum vulgar e como educadores ações coletivas de formação permanente na superação do modelo acrítico e conservador de educação em linhas gerais no Brasil. A fragmentação social e das organizações torna cada vez mais difícil essa tarefa. Torna-se evidente a superação da obviedade conservadora. Urge criação coletiva critica e criativa na produção de alternativas possíveis.

Por fim, e com a clareza que um texto por melhor que esteja não se finda, mas levanta novas construções, chego à conclusão desse trabalho com algumas perguntas acredito que de forma breve respondidas, ou me levou a novas perguntas. Espero que o leitor possa se sentir instigado a perguntar e ir a raiz dos problemas aqui levantados.

Ao longo dos meus vinte e cinco anos de educador já estive presente em diversas ações educacionais. Desde a educação infantil até o ensino superior, passando praticamente por todos os níveis de ensino. Tive a oportunidade de trabalhar em escolas particulares no ensino fundamental e posteriormente na faculdade. Trabalhei também numa escola comunitária, sede de um movimento popular como alfabetizador e depois como coordenador. Na escola pública na rede estadual como professor do ensino fundamental polivalente. Como pedagogo e coordenador na escola Normal. Fui professor substituto na Universidade Federal de Sergipe e atualmente sou professor efetivo no Instituto Federal de Educação, Ciência e Tecnologia de Sergipe lotado no curso de Licenciatura em Física. Ensino as disciplinas pedagógicas. Durante este tempo fui Educador Popular e coordenador da ONG Centro Sergipano de Educação Popular (CESEP). E hoje sou membro pesquisador, desde 1998 do Núcleo de Pesquisa Sociedade e Educação - NPSE e do Grupo de Estudos e Pesquisas História, sociedade e Educação no Brasil em Sergipe (HISTEDBR/SE).

. Procurei expor meu processo como profissional em educação e pretenso intelectual orgânico da classe que vive do trabalho, segundo as formulações gramscianas, a fim de ressaltar que é essencial o conhecimento teórico e prático no fazer educativo em que estamos inseridos. Hoje mais do que nunca requer que assumamos uma atitude radical. Ir na profundidade das coisas. Estar ligados ao desenvolvimento de novas tecnologias, não para ser dominado por elas, mas no fazer criativo saber usá-la vinculando o saber tecnológico, com o saber cientifico, com o saber pedagógico e com o saber filosófico em geral. Nós educadores hoje somos praticamente chamados a cruzar os braços devido a tantos fatores desestimulantes no que fazer educativo das escolas públicas como salários baixos, péssimas condições de trabalho, dificuldade de progredir nos estudos na pósgraduação, no mestrado e doutorado, violência na escola e na sociedade. As dificuldades são muitas, e, principalmente de acreditar que a história acabou que as transformações sociais e culturais não são possíveis...

Na contramão dessa dita obviedade pretendo acreditar que a história é um processo, que o processo educativo é criativo e transformador, que a história está nas nossas mãos para transformá-la, como diz Geraldo Vandré "Vem vamos embora, esperar não é saber, 
quem sabe faz a hora não espera acontecer". Acredito que fazemos a hora participando concretamente nas lutas sociais de classe, desenvolvendo a dialética do concreto como mostra Karel Kosik e quando aprofundamos categorias marxianas como a historicidade. $\mathrm{Ou}$ seja teoria e prática, ação e reflexão, objetividade e subjetividade é um todo que se constrói nas práticas e relações sociais e humanas.

Espero ter contribuído para o campo da história da educação. Mesmo com todos os riscos de quem está apenas no começo, mas pretende continuar caminhando. Acredito que há diversas lacunas, contudo busquei explicitar problemas evidentes no campo educacional decorrente do auge do pós-modernismo no Brasil. Foi uma tentativa também de reivindicar à liberdade de pensamento, inclusive da liberdade de escrever de forma autônoma. O que na universidade está cada vez mais difícil.

\section{REFERÊNCIAS}

ANDERSON, Perry. A Origem da Pós-Modernidade - Rio de Janeiro: Zahar, 1999.

CASTANHO, Sérgio E. M. Questões teórico-metodológicas de História Cultural IN: História, cultura e educação / José Claudinei Lombardi; Ana Palmira Bittencourt Santos Casimiro e Lívia Diana Rocha Magallhães (orgs). - Campinas, SP: Autores Associados, 2006. (Coleção educação contemporânea).

DUARTE, Newton. Vigotski e o "aprender a aprender": crítica às apropriações neoliberais e pós-modernas das teorias vigotskiana - $4^{\mathrm{a}} \mathrm{ED}-\mathrm{Campinas,} \mathrm{SP:} \mathrm{Autores}$ Associados, 2006. (Coleção educação contemporânea).

HALL, Stuart. A Identidade Cultural na Pós-Modernidade / Stuart Hall: tradução Tomaz Tadeu da Silva, Guaracira Lopes Louro - 11. Ed. 1. Reimp. - Rio de Janeiro: DP\&A, 2011.

JAMESON, Fredric. Pós-Modernismo: A lógica cultural do capitalismo tardio. $2^{\text {a }}$ Ed. São Paulo: Ática, 1997.

LOMBARDI, José Claudinei. História, cultura e educação: aportes marxistas. IN: História, cultura e educação / José Claudinei Lombardi; Ana Palmira Bittencourt Santos Casimiro e Lívia Diana Rocha Magallhães (orgs). - Campinas, SP: Autores Associados, 2006. (Coleção educação contemporânea).

NETO, José Paulo. Os desafios epistemológicos e metodológicos da pesquisa histórica. IN: Seminário do grupo de Estudos e Pesquisas História, Sociedade e Educação de Sergipe Região Nordeste. (1998- São Cristovão-SE). A pesquisa histórico-educacional impasses e desafios São Cristovão, 2002.

SANFELICE, José Luis. Pós-Modernidade, Globalização e Educação. IN: LOMBARDI, José Claudinei (Org). Globalização, Pós Modernidade e Educação: história, filosofia e temas transversais. $3^{\mathrm{a}}$ Ed. - Campinas, SP: Autores Associados: HISTEDBR; Caçador, SC: UnC, 2009. - (Coleção educação contemporânea).

ROUANET, Sérgio P. As razões do iluminismo. São Paulo: Companhia das Letras, 1987. Recebido: julho-15 Aprovado: agosto-15 